\title{
A Method Based on the Theory of Small Reflections to Design Arbitrary Passband Microstrip Filters
}

\author{
Ye YUAN, Weiwei WU, Wentao YUAN, Shuang WU, Naichang YUAN \\ College of Electronic Science and Engineering, National University of Defense Technology, \\ Changsha, Hunan, 410073, China \\ 776411434@qq.com
}

Submitted July 31, 2017 / Accepted February 4, 2018

\begin{abstract}
A$ method to design a kind of microstrip filters consisting of only opened stubs and shorted stubs is proposed in this paper. This method is based on the Theory of Small Reflections, and the equations to calculate dimensions of this type of filters are exhibited. Two filters developed by our method are simulated and fabricated. The first filter has a passband on 5 8 GHz. The second one is a dual-band filter and can work on both $2.4 \mathrm{GHz}$ and $5.8 \mathrm{GHz}$. By using our method, the designed filters only contain opened stubs and shorted stubs, therefore, it is easy to design and fabricate this type of filters. The comparison between calculated and measured reflection coefficient curves shows a satisfactory fitting degree, this manifestation verifies that the method in our paper has a good application in filter design. The positions of transmission zeros about the second filter are investigated. All the results show that our method can be a good guidance in microstrip filter design.
\end{abstract}

\section{Keywords}

Theory of Small Reflections, reflection coefficient, broadband filter, dual-band filter

\section{Introduction}

Microstrip filters has been widely used in a large number of RF applications. As the wireless communication system is developing rapidly [1], it is important to hunt for some convenient method to design microstrip filters [2-6]. Our paper establishes a new method to design stub-loaded filters. This kind of filters contains only opened stubs and shorted stubs, and our filters have the characteristics of simple construction and small size. Also, the frequency response of our filters can be designed for arbitrary shape. Therefore, this new type of filters has plenty of RF applications.

The Theory of Small Reflections is to consider the reflection coefficients among adjacent transmission lines as the coefficients of Fourier expansion of total reflection function [7-13]. The conventional application of this the- ory is impedance matching design between load and source, the reflection coefficient at the input port will be nice and small while using this technology [14-21]. In [22], the microstrip feeding for an antenna is designed based on the Theory of Small Reflections, the return loss of the designed antenna is around $-60 \mathrm{~dB}$ at $5.8 \mathrm{GHz}$, and it proves that the good performance of this theory in matching design. Stepped-impedance filters also apply this theory to obtain good designs, particularly in low-pass filters (LPFs) design. In [23], the section of the substrate is disposed to influence the impedance of microstrip line, a LPF based on the stepped impedance structure is designed. The cut-off frequency of its passband is about $1 \mathrm{GHz}$ and has a good performance in the passband. But the fabrication of this filter can be difficult due to inhomogeneous substrate. When a design of bandpass filters (BPFs) or broadband filters is required, the stepped-impedance filters cannot perform well because the ideal stepped-impedance structures are usually hard to implement in reality. In [24], the authors presented the modified Theory of Small Reflections and used it to design a bandpass filter. In this paper, the profile of stepped-impedance structures is considered as a non-uniform transmission line which is determined from the desired reflection coefficient of the device and a filter with passband on $5 \sim 7 \mathrm{GHz}$ is designed.

This paper takes advantages of the theory to design filters with arbitrary passband. The total reflection function of stepped-impedance filters can be decomposed by Fourier expansion. It is important to focus on the coefficients of each expansion term, because each term represents the local reflection coefficient between adjacent sections of the stepped-impedance filters [25-27]. By loading the opened stubs and shorted stubs on every section of transmission lines to transforming their characteristic impedance as complex number, it is possible for us to render the local reflection coefficients as frequency response functions. At last, a total reflection coefficient can be obtained as zero at the input port.

Two examples of our filters are designed, fabricated and measured in Sec. 3 in order to verify that our theory has the feasibility in filters design. The first filter has a passband between $5 \mathrm{GHz}$ and $8 \mathrm{GHz}$, and can be used in broadband situation. The second one is a dual-band filter 
which is working on both $2.4 \mathrm{GHz}$ and $5.8 \mathrm{GHz}$, it has some application of signal transmission both in civil-used and military-used areas. Both two filters have the same structures and can be designed and fabricated easily. These two filters also illustrate that our method can cover the shortage of general stepped-impedance filters. The measured results of frequency response of our filters are shown in Sec. 3. Both reflection curves and insert-loss curves of our filters show satisfactory performance. The comparison between calculated results and measured results match well with each other. The relationship between the length of loaded stubs and the position of transmission zeros (TZs) is also presented and it provides some guidance in design of out-of-band attenuation for single-passband filters.

\section{Calculation about Total Reflection Coefficients of Stepped-impedance Structure}

In [28], author shows the method to obtain the reflection coefficient of a multiple-stub impedance transformer. The equivalent model for the transformer is depicted in Fig. 1.

The reflection coefficient at the input port $\Gamma_{\text {Total }}$ is given in (1) where $\theta$ is the length of each stub. $Z_{n}$ is the characteristic impedance of each transmission line, $Z_{\mathrm{L}}$ is the load impedance, $\Gamma_{n}$ is the reflection coefficient of each part, and $\Gamma_{n}$ is also a real number

$$
\Gamma_{\text {Total }}(\theta)=\sum_{n=0}^{N} \Gamma_{n} \exp (-\mathrm{j} 2 n \theta) .
$$

The derivation process of (1) is known as the Theory of Small Reflections. From (1), it is easy to perceive that $\Gamma_{\text {Total }}$ is a function depending on $\theta$ and $\Gamma_{n}$. In Theory, equation (1) can match arbitrary $\Gamma_{\text {Total }}$ curve by meticulous design of $\theta$ and $Z_{n}$.

But in reality, on account of some compulsive restrictions, this method is hard to implement in filter design, especially for broadband situations. Ref. [24] shows a filter designed by the theory of small reflection, but the bandwidth of its passband is only about $2 \mathrm{GHz}$, and the out-ofband rejection is about $-10 \mathrm{~dB}$, obviously this filter does not perform well. To cover this shortage, our paper brings in the load stub in order to add imaginary part on the characteristic admittance $Y_{\mathrm{Im}}$ of transmission lines. The structure of parallel loading opened stub and shorted stub are shown in Fig. 2 and Fig. 3 where $\theta_{1}$ represents the electrical length of stub, $Y_{0}$ represents the characteristic admittance of

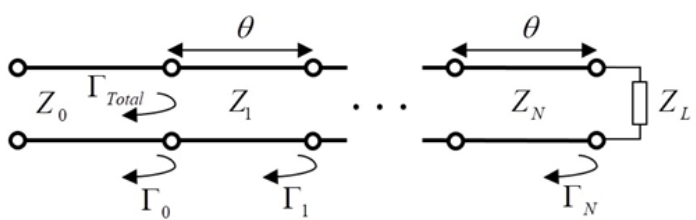

Fig. 1. The equivalent model for multiple-stub impedance transformer.

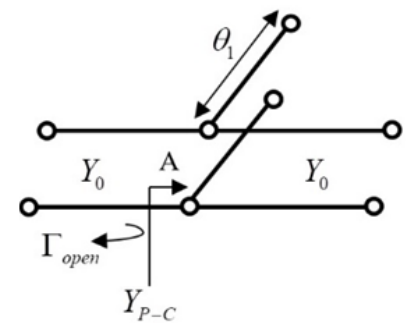

(a)

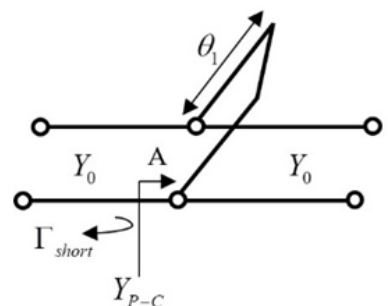

(b)
Fig. 2. Parallel loading of opened stub and shorted stub: (a) Opened stub. (b) Shorted stub.

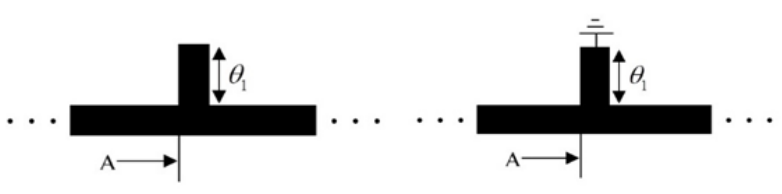

(a)

(b)

Fig. 3. Microstrip structures of Fig. 2: (a) Opened stub. (b) Shorted stub.

the main transmission line, $Y_{\mathrm{P}-\mathrm{C}}$ represents the equivalent admittance at point $\mathrm{A}$ (parallel combination of the main line and the stub) both in Fig. 2 (a) and (b).

According to the Transmission Line Theory, the reflection coefficients at point $\mathrm{A}\left(\Gamma_{\text {open }}, \Gamma_{\text {short }}\right)$ are proven to be:

$$
\begin{gathered}
\Gamma_{\text {open }}=\frac{-\mathrm{j}}{\mathrm{j}+2 \cot \theta_{1}}, \\
\Gamma_{\text {short }}=\frac{\mathrm{j}}{2 \tan \theta_{1}-\mathrm{j}} .
\end{gathered}
$$

By putting (2) and (3) into (1), it allows us to endow other variables into the $\Gamma_{\text {Total }}$ function. Considering the structure of Fig. $4, \Gamma_{\text {Total }}$ can be written as a function of frequency $f$

$$
\begin{gathered}
Y_{n}=Y_{0}+Y_{\mathrm{Im}} \\
\Gamma_{n}\left(L_{n}, L_{n+1}, f\right)=\frac{Y_{n}\left(L_{n}\right)-Y_{n+1}\left(L_{n+1}\right)}{Y_{n}\left(L_{n}\right)+Y_{n+1}\left(L_{n+1}\right)}, \\
\Gamma_{\text {Total }}(f)=\sum_{n=0}^{N} \Gamma_{n}\left(L_{n}, L_{n+1}, f\right) \exp \left(-\mathrm{j} \frac{4 \pi n L}{c} f\right)
\end{gathered}
$$

where $Y_{\text {Im }}$ represents the equivalent admittance of loaded stubs. $L_{n}$ is the physical length of each loading stub, $L_{0}$ and $L_{N+1}$ equal to zero. $L$ is the length of each section of the main transmission line. $c$ is the velocity of light. $\Gamma_{n}\left(L_{n}, L_{n+1}, f\right)$ is given according to (5). By using (6) rather

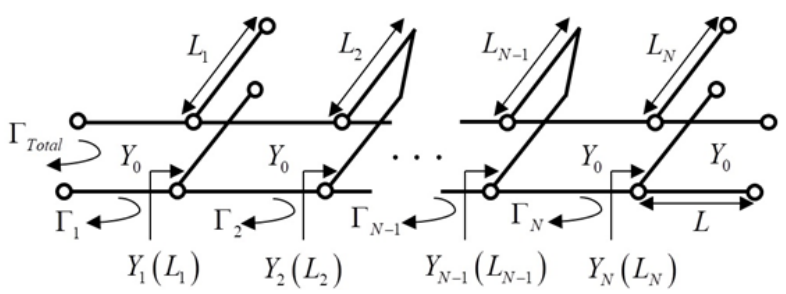

Fig. 4. Equivalent model of multiple-stub tuning structure. 
than (1), $\Gamma_{n}$ will be a plural number, more complex $\Gamma_{\text {Total }}$ curves can be matched. The calculated transmission $\mathrm{S}$ parameter $\left|S_{21}^{\text {cal }}(f)\right|$ of our filters can be specified as (7):

$$
\left|S_{21}^{\text {Cal }}(f)\right|^{2}=1-\left|\Gamma_{\text {Total }}(f)\right|^{2} \text {. }
$$

\section{Microstrip Filter Design Procedures and Numerical Results}

This section provides the design procedures about the microstrip filter based on (7). The main ideas of our design procedures are as follows.

First we need to select the frequency band that we are interested in, second we set the magnitude value of objective function curve $\left|S_{21}^{\text {Itcal }}\right|$ as $0 \mathrm{~dB}$ in the passband and $-20 \mathrm{~dB}$ in the stopband. Then we use the gradient optimization algorithm to find the minimum error between the $\left|S_{21}^{\text {Cal }}(f)\right|$ function and $\left|S_{21}^{\text {ddeal }}\right|$ curve. The details of gradient optimization are shown in [29]. We can combine $\left|S_{21}^{\text {cal }}\right|$ and $\left|S_{21}^{\text {tdeal }}\right|$ in error function as (8):

$$
\begin{gathered}
E(\mathbf{L})=\left.\sum_{n=1}^{N}|| S_{21}^{\text {Cal }}\left(\mathbf{L}, f_{n}\right)\right|^{2}-\left|S_{21}^{\text {Ideal }}\left(\mathbf{L}, f_{n}\right)\right|^{2} \mid, \\
\mathbf{L}^{*}=\underset{\mathbf{L} \geq 0}{\arg \min } E(\mathbf{L})
\end{gathered}
$$

where the $\mathbf{L}$ is the vector form of $L_{n}, \mathbf{L}^{*}$ is the optimal solution of $\mathbf{L}, f_{n}$ is the average sample on the frequency band. By calculating the directional derivative about $E(\mathbf{L})$ along the direction of $\mathbf{L}$, then we can update the new $\mathbf{L}$ as (10):

$$
\mathbf{L}=\mathbf{L}-\alpha \nabla_{\mathbf{L}} E(\mathbf{L})
$$

where $\alpha$ is the learning rate, it controls the velocity of gradient descent. Here we set the value of $\alpha$ as 0.0035 . After the updating, we put the new $\mathbf{L}$ into (8) to start the next calculation. By setting a maximum error $\varepsilon_{\max }$, we can stop the iteration when equation (8) is lesser than $\varepsilon_{\max }$. Finally we can obtain the optimal result of $\left|S_{21}^{\text {cal }}\right|^{*}$ (the optimal approximating about $\left.\left|S_{21}^{\text {dical }}\right|\right)$.

Two microstrip filters are designed as examples in this section. The first one (Filter 1) has a passband on $5 \sim 8 \mathrm{GHz}$, and it is an example for broadband filters. The second one (Filter 2) can work both on $2.4 \mathrm{GHz}$ and $5.8 \mathrm{GHz}$, and it is a narrowband and dual-band filter.

At the very beginning, we need to prescribe some limits to our filters. If the order $N$ is stipulated as 10 , the complex rate of optimize process can be moderate. We also use the point symmetric structure to transform (6) into (11) (by using the Euler's function [28]), it can greatly simplify the design process.

$$
\begin{aligned}
& \Gamma_{\text {Total }}(f)= \\
& 2 \mathrm{j} \exp \left(-\mathrm{j} \frac{24 \pi L}{c} f\right) \sum_{n=0}^{5} \Gamma_{n}\left(L_{n}, L_{n+1}, f\right) \sin \left(\frac{4 \pi n L}{c} f\right) .
\end{aligned}
$$

\begin{tabular}{|c|c|c|}
\hline Band Selection & Passband [GHz] & Stopband [GHz] \\
\hline Filter 1 & $5 \sim 8$ & $4 \sim 5$ and $8 \sim 9$ \\
\hline Filter 2 & $2.2 \sim 2.6$ and 5.7 5.9 & $1 \sim 2.2$ and 5.9 7 \\
\hline
\end{tabular}

Tab. 1. Passband and stopband of both Filter 1 and Filter 2.

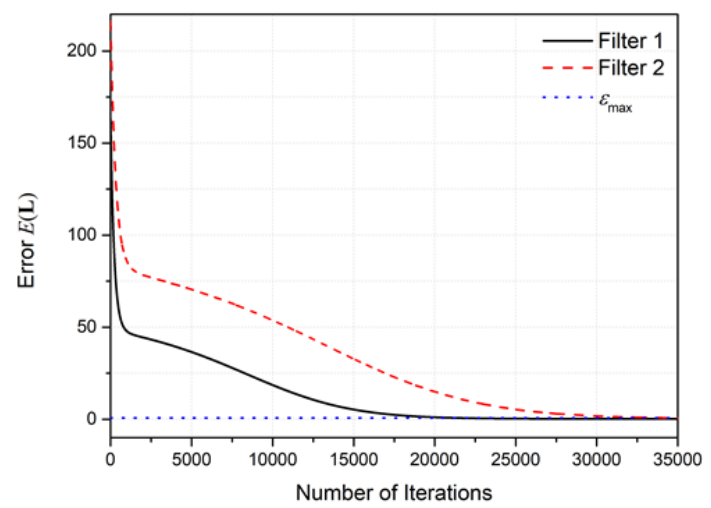

Fig. 5. $E(\mathbf{L})$ of each iteration.

The selected frequency bands of each filter are shown in Tab. 1. Then we use the process mentioned above to calculate the dimensions of loaded stubs. The calculated $E(\mathbf{L})$ of each iteration are shown in Fig. 5. Here, $\varepsilon_{\max }$ is set to be equal to 1 .

The calculation results of length of each stub will guide us to build the simulation models in EM simulation software. Then the properties of filters are optimized by the EM simulation software in order to determine the real length of each stub. All the calculation and simulation results are listed in Tab. 2 and Tab. 3. The final structures of our filters are shown in Fig. 6. Both filters are designed by using Rogers RO4350 substrate of dielectric constant 3.66 and substrate height $0.762 \mathrm{~mm}$ (30mil). The widths of the stubs $W$ are all the same. The spacing between two neighboring stubs $W_{1}$ is equal to $W$.

The fabricated filters are shown in Fig. 7. The shorted stubs can be achieved by via holes at the end of opened stubs. In Fig. (a), part A and part B are the same filterFilter 1, they are cascaded as one filter in order to obtain higher out-of-band rejection.

\begin{tabular}{|c|c|c|}
\hline Stubs of Filter 1 & $\begin{array}{c}\text { Calculated } \\
\text { Dimension [mm] }\end{array}$ & $\begin{array}{c}\text { Practical } \\
\text { Dimension [mm] }\end{array}$ \\
\hline$W$ & 2 & 1.6 \\
\hline$L_{1}$ & 5 & 5.8 \\
\hline$L_{2}$ & 3.8 & 3.8 \\
\hline$L_{3}$ & 4.9 & 4.1 \\
\hline$L_{4}$ & 1 & 1 \\
\hline$L_{5}$ & 8.2 & 8.3 \\
\hline
\end{tabular}

Tab. 2. Length of stubs of Filter 1.

\begin{tabular}{|c|c|c|}
\hline Stubs of Filter 2 & $\begin{array}{c}\text { Calculated } \\
\text { Dimension [mm] }\end{array}$ & $\begin{array}{c}\text { Practical } \\
\text { Dimension [mm] }\end{array}$ \\
\hline$W$ & 3.8 & 3.6 \\
\hline$L_{1}$ & 3 & 4.4 \\
\hline$L_{2}$ & 11.5 & 11.2 \\
\hline$L_{3}$ & 9 & 9.5 \\
\hline$L_{4}$ & 2.8 & 1.6 \\
\hline$L_{5}$ & 9.3 & 11.3 \\
\hline
\end{tabular}

Tab. 3. Length of stubs of Filter 2 . 


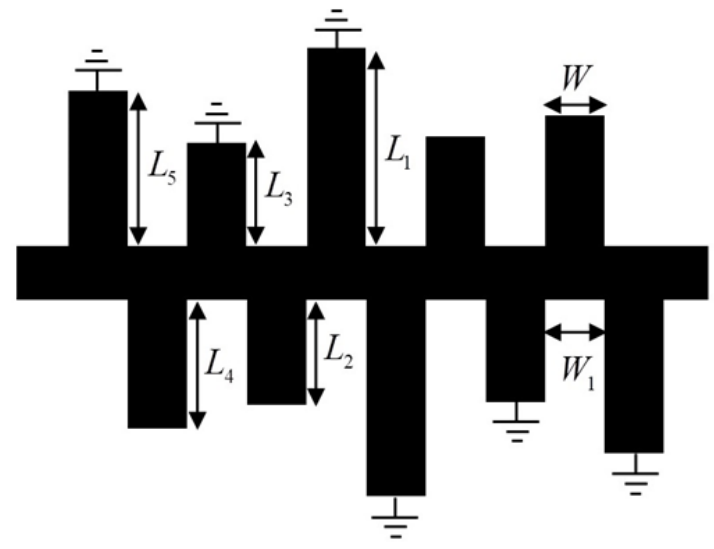

Fig. 6. Final structure of filters.

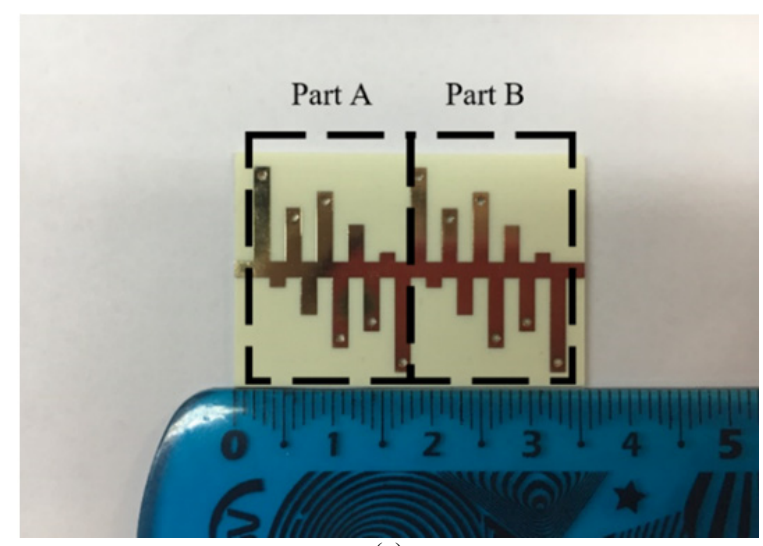

(a)

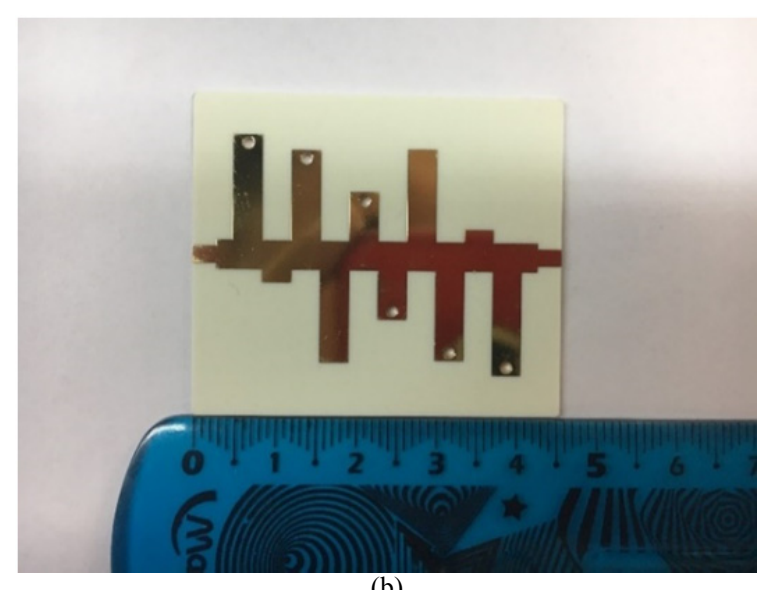

(b)

Fig. 7. Fabricated filters: (a) Filter 1, (b) Filter 2.

\begin{tabular}{|c|c|c|}
\hline Characters & Filter 2 & Filter in [30] \\
\hline$f_{0}[\mathrm{GHz}]$ & 2.4 and 5.8 & 2.45 and 5.8 \\
\hline FBW [\%] & 16.7 and 7 & 12 and 7 \\
\hline Length [mm] & 4.5 & 13 \\
\hline
\end{tabular}

Tab. 4. Comparison between Filter 2 and filter designed in [30].

We can tell from Fig. 6 , by setting $W$ be equal to $W_{1}$, we can obtain the miniaturized filters. Here is a comparison between Filter 2 and a fifth-order Chebyshev filter designed in [30]. The comparison results are shown in Tab. 4, where $f_{0}$ represents the center frequency of the passband, FBW represents the Fractional Bandwidth of the passband.
Table 4 shows that our filters can be good candidates for use primarily as integrated and miniaturized filters.

After the manufacture, the frequency response of each filter is measured on the vector network analyzer (VNA). Figure 8 gives out the comparisons between the calculation results and measurement results of total reflection coefficient $\left|S_{11}\right|$ and the insertion loss $\left|S_{21}\right|$. The numerical data of insertion loss in both filters are given as appendix (Tab. 5 and 6).

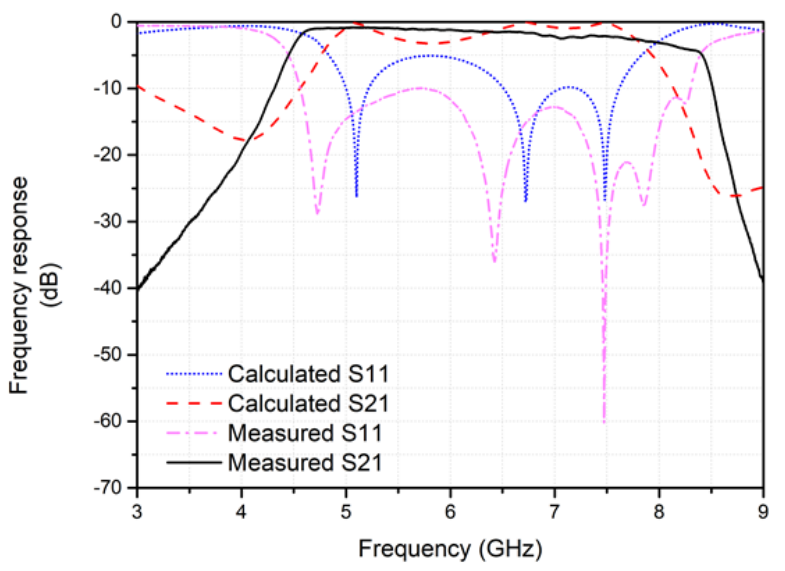

(a)

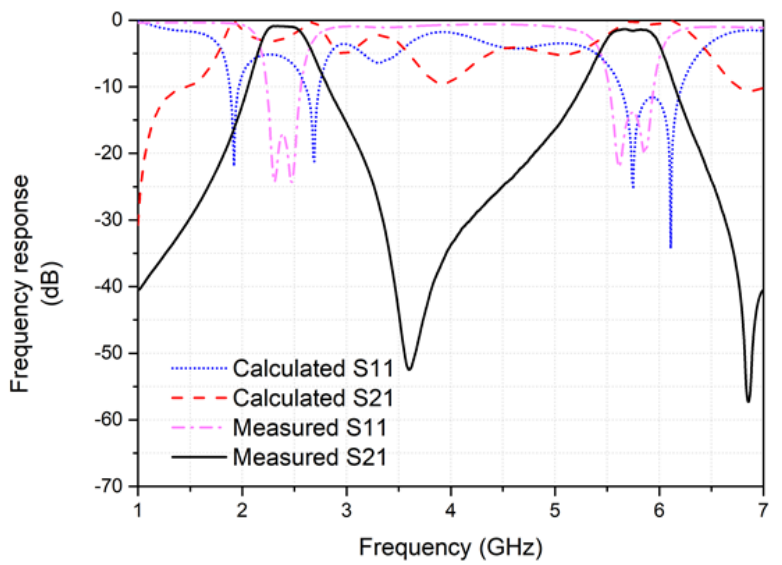

(b)

Fig. 8. Comparison of $\left|S_{11}\right|$ and $\left|S_{21}\right|$ curves: (a) Filter 1, (b) Filter 2.

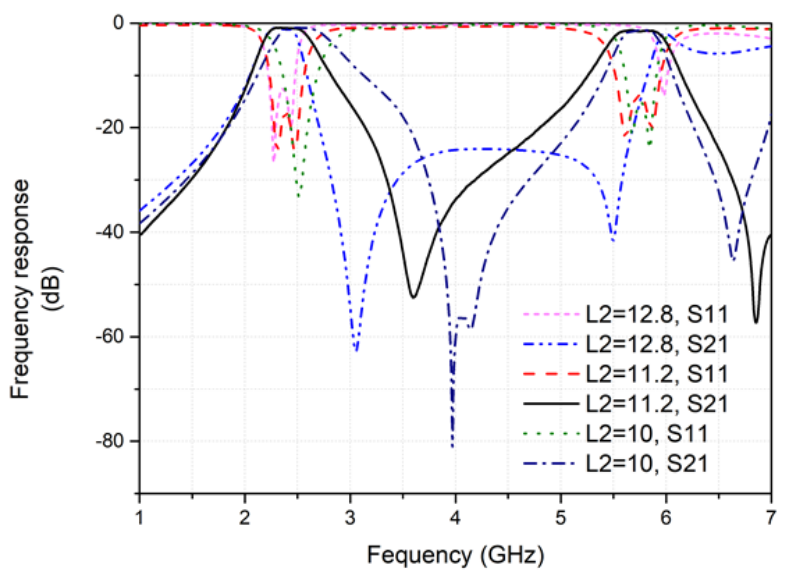

Fig. 9. The influence of length of $L_{2}$ on the position of $\mathrm{TZ}_{1}$, the unit of $L_{2}$ is $\mathrm{mm}$. 
The above response shows that the calculation results match well with measured curves. In Fig. 8(a), it has an evident passband between $5 \mathrm{GHz}$ and $8 \mathrm{GHz}$. In Fig. 8(b), the center frequency of the passband is around $2.4 \mathrm{GHz}$ and $5.7 \mathrm{GHz}$. It is obvious that each filter has good performance both in passband and stop-band. The final $3 \mathrm{~dB}$ passband of Filter 1 is $4.5 \sim 8.3 \mathrm{GHz}$, for Filter 2 there are 2.2 2.6 GHz and 5.5 5.9 GHz. The goal is that reflection coefficient in both passband is lower than $-10 \mathrm{~dB}$. These two filters also illustrate that the theory in this paper can be applied both for broadband and narrowband situations.

We can also tell from Fig. 8(b) that there are two TZs in Filter 2, located approximately at $3.5 \mathrm{GHz}\left(\mathrm{TZ}_{1}\right)$ and $6.8 \mathrm{GHz}\left(\mathrm{TZ}_{2}\right)$. By changing the length of stubs, we can control the position of such TZs. For example, we can increase or decrease $L_{2}$ to move the $\mathrm{TZ}_{1}$ close to the first passband or close to the second passband. The simulation results are shown in Fig. 9. Figure 9 shows that when $L_{2}$ equals to $10 \mathrm{~mm}$, the transmission characteristics within the second passband is good. When $L_{2}$ reaches $12.8 \mathrm{~mm}$, the second passband becomes missing, but a sharp roll-off occurs at the high side of the first passband. So, as $L_{2}$ becomes longer, $\mathrm{TZ}_{1}$ would get close to the first passband, and the out-of-band attenuation of the first passband become sharper, but it has little effect on the transmission characteristics within this passband. It concludes that we can change the position of TZs to obtain better out-of-band attenuation, the cost is that the performance of another passband would be worse. This conclusion has some guidance in single-passband filter design, but in this paper we choose the optimal position of $\mathrm{TZ}_{1}$ to design our dual-band filters to ensure that both passbands perform well.

\section{Conclusion}

In this paper, a method of microstrip filter design based on the theory of small reflection has been investigated. Section 2 gives out the details of calculation procedure. In Sec. 3, two examples of filters have been designed, fabricated and measured, both filters only contain opened and shorted stubs. The calculated length and the practical length of each stub are listed in Sec. 3, the comparison between them shows that the fitting degree of calculated dimension and actual dimension of our filters performs well. The measured reflection coefficient and calculated reflection coefficient are also compared in Sec. 3, the results of comparison verify that our method can match well with the real reflection coefficient curves. The fabricated filters have satisfactory frequency response, both reflection coefficient curves and insert-loss curves meet the requirement. The relationship between positions of TZs and the out-of-band attenuation about Filter 2 is investigated. In conclusion, our method can be a good guidance in microstrip filter design.

\section{References}

[1] ANGUERA, J., ANDUJAR, A., HUYNH, M. C., ORLENIUS, C., et al. Advances in antenna technology for wireless handheld devices. International Journal on Antennas and Propagation, 2013, 25 p. DOI: $10.1155 / 2013 / 838364$

[2] EL-HALABI, H., ISSA, H., PISTONO, E., KADDOUR, D., et al. Compact low-pass stepped impedance filters with enhanced out of band response. Microwave and Optical Technology Letters, 2017, vol. 59 , no. 8 , p. 1791-1800. DOI: $10.1002 /$ mop.30635

[3] GAN, D. C., HE, S. B., DAI, Z. J., et al. A quad-band bandpass filter using split-ring based on T-shaped stub-loaded steppedimpedance resonators. Microwave and Optical Technology Letters, 2017, vol. 59, no, 8, p. 2098-2104. DOI: 10.1002/mop.30684

[4] LI, R., ZHU, L. Compact UWB bandpass filter using stub-loaded multiple-mode resonator. IEEE Microwave and Wireless Components Letters, 2007, vol. 17, no. 1, p. 40-42. DOI: 10.1109/LMWC.2006.88725

[5] KUO, J. T., SHIH, E. Microstrip stepped impedance resonator bandpass filter with an extended optimal rejection bandwidth, IEEE Transactions on Microwave Theory and Techniques, 2003, vol. 51, no. 5, p. 1554-1559. DOI: 10.1109/TMTT.2003.810138

[6] DING, L., WANG, X. Z., ANG, N. S. S., et al. Ultrathin film broadband terahertz antireflection coating based on impedance matching method. IEEE Journal of Selected Topics in Quantum Electronics. 2017, vol. 23, no. 4, 8 p. DOI: 10.1109/JSTQE.2016.2629666

[7] ZHANG, Y. P., SUN, M. Dual-band microstrip bandpass filter using stepped-impedance resonators with new coupling schemes. IEEE Transactions on Microwave Theory and Techniques, 2006, vol. 54, no. 10, p. 3779-3785. DOI: 10.1109/TMTT.2006.882895

[8] TORRUNGRUENG, D., THIMAPORN, C., LAMULTEE, S., et al. Theory of small reflections for conjugately characteristicimpedance transmission lines. IEEE Microwave and Wireless Components Letters, 2008, vol. 18, no. 10, p. 659-661. DOI: 10.1109/LMWC.208.2003450

[9] TORUNGRUENG, D., THIMAPORN, C. A generalized ZY Smith chart for solving nonreciprocal uniform transmission-line problems. Microwave and Optical Technology Letters, 2004, vol. 40, no. 1, p. 57-61. DOI: 10.1002/mop.11284

[10] HUANG, Y., BAO, J. F., TANG, G. B., et al. Design consideration of SAW/BAW band reject filters embedded in impedance converter. IEEE Transactions on Ultrasonics, Ferroelectrics, and Frequency Control, 2017, vol. 64, no. 9, p. 1368-1374. DOI: 10.1109/TUFFC.2017.2713395

[11] ORAIZI, H., MORADIAN, M., HIRASAWA, K. Design and optimization of microstrip parallel-coupled-line bandpass filters incorporating impedance matching. IEICE Transactions on Communications, 2006, vol. E89B, no. 11, p. 2982-2989. DOI: 10.1093/ietcom/e89-b.11.2982

[12] WU, Y. L., LIU, Y. N., LI, S. L. A dual-frequency transformer for complex impedances with two unequal sections. IEEE Microwave and Wireless Components Letters, 2009, vol. 19, no. 2, p. 77-79. DOI: 10.1109/LMWC.2008.2011315

[13] CHOW, Y. L., WAN, K. L. A transformer of one-third wavelength in two sections - for a frequency and its first harmonic. IEEE Microwave and Wireless Components Letters, 2002, vol. 12, no. 1, p. 22-23. DOI: $10.1109 / 7260.975723$

[14] LOPEZ, A. R. Double-tuned impedance matching. IEEE Antennas and Propagation Magazine, 2012, vol. 54, no. 2, p. 109-116. DOI: 10.1109/map.2012.6230722 
[15] KIROV, G. S., ABDEL-RAHMAN, A., NADIM, G., et al. Impedance matching improvement for a class of wideband antennas. IEEE Antennas and Propagation Magazine, 2004, vol. 46, no. 6, p. 98-101. DOI: 10.1109/MAP.2004.1396743

[16] PARK, M. J., LEE, B. Dual-band design of single-stub impedance matching networks with application to dual-band stubbed Tjunctions. Microwave and Optical Technology Letters, 2010, vol. 52, no. 6, p. 1359-1362. DOI: 10.1002/mop.25201

[17] DUTTA ROY, S. C. Characteristics of single- and multiplefrequency impedance matching networks. IEEE Transactions on Circuits and Systems II-Express Briefs, 2015, vol. 62, no. 3, p. 222-225. DOI: 10.1109/TCSII.2014.2368973

[18] DUTTA ROY, S. C. Network design for multiple frequency impedance matching by the frequency transformation technique. IETE Journal of Research, 2013, vol. 59, no. 6, p. 698-703. DOI: $10.4103 / 0377-2063.126966$

[19] DEMIR, S. Design of wideband impedance transformers. IEEE Antennas and Propagation Magazine, 2003, vol.45, no. 5, p. 71 to 72. DOI: 10.1109/MAP.2003.6176015

[20] ORFANIDIS, S. J. A two-section dual-band Chebyshev impedance transformer. IEEE Microwave and Wireless Components Letters, 2003, vol. 13, no. 9, p. 382-384. DOI: 10.1109/LMWC.2003.817135

[21] MARTINS, G. C., SERDIJN, W. A. Multistage compleximpedance matching network analysis and optimization. IEEE Transactions on Circuits and Systems II-Express Briefs, 2016, vol. 63, no. 9, p. 833-837. DOI: 10.1109/TCSII.2016.2534738

[22] OLOKEDE, S. S., PAUL, B. S. A novel microstrip feed based on the theory of small reflection. In IEEE Radio \& Antenna Days of the Indian Ocean. St. Gilles-les-Bains (Reunion), 2016, p. 1-2. DOI: 10.1109/RADIO.2016.7772018

[23] PRODROMAKIS, T., PAPAVASSILIOU, C., MICHELAKIS, K. Microstrip stepped impedance lowpass filters based on the Maxwell-Wagner polarization mechanism. In IEEE International Symposium on Circuits \& Systems. Seattle (WA, USA), 2008, p. 616-619. DOI: 10.1109/ISCAS.2008.4541493

[24] CESAR-DE-ALENCAR， D., MENEZES, R. A. X. Direct synthesis of microwave filters using modified small reflections theory. In 1999 SBMO/IEEE MTT-S International Microwave and Optoelectronics Conference. Rio-de-Janeiro (Brazil), 1999, vol. 1, p. 183-186. DOI: 10.1109/IMOC.1999.867085

[25] DAI, G. L., ZHANG, X. Y., CHAN, C. H., et al. An investigation of open- and short-ended resonators and their applications to bandpass filters. IEEE Transactions on Microwave Theory and Techniques, 2009, vol. 57, no. 9, p. 2003-2210. DOI: 10.1109/TMTT.2009.2027173

[26] ORAIZI, H., ESFAHLAN, M. S., FORATI, E. Design of steppedimpedance low pass filters with impedance matching by the particle swarm optimization and conjugate gradient method. In European Conference on Circuit Theory and Design. Antalya (Turkey), 2009, p. 639-642. DOI: 10.1109/ECCTD.2009.5275068

[27] SONG, C. T. P., HALL, P. S., GHAFOURI-SHIRAZ, H., et al. Sierpinski monopole antenna with controlled band spacing and input impedance. Electronic Letters, 1999, vol. 36, no. 13, p. 1036-1037. DOI: 10.1049/el:19990748

[28] POZAR, D. M. Microwave Engineering. 3rd ed. New York (USA) John Wiley and Sons Ltd., 2005. ISBN: 8126510498
[29] RUSSELL, S. J., NORVIG, P. Artificial Intelligence: a Modern Approach. 3rd ed. Prentice Hall, 2010. ISBN: 0136042597

[30] KUO, J. T., YEH, T. H., YEH, C. C. Design of microstrip bandpass filters with a dual-passband response. IEEE Transactions on Microwave Theory and Techniques, 2005, vol. 53, no. 4, p. 1331-1337. DOI: 10.1109/TMTT.2005.845765

\section{About the Authors ...}

Ye YUAN was born in 1994. He received his B.S. degree in Electronic Science and Technology from the Nanjing University of Aeronautics and Astronautics in 2016. Currently he is working towards the M.S. degree in the College of Electronic Science and Engineering, National University of Defense Technology, Changsha, Hunan, China. His research interests include passive microwave circuits design and wireless communication.

Weiwei WU was born in 1981. She received her M.S. and $\mathrm{Ph} . \mathrm{D}$. degree in Electronic Science and Technology from the National University of Defense Technology in 2008 and 2011, respectively. Currently she is a teacher in the College of Electronic Science and Engineering, National University of Defense Technology, Changsha, Hunan, China. Her research interests include antennas design and wave propagation.

Wentao YUAN was born in 1990. He received his B.S. degree in Computer Science and Technology from the Anhui Normal University in 2016. Currently he is working towards the M.S. degree in the College of Electronic Science and Engineering, National University of Defense Technology, Changsha, Hunan, China. His research interests include passive microwave circuits design and wireless communication.

Shuang WU was born in 1993. He received his B.S. degree in Electronic Science and Technology from the Xidian University in 2015. Currently he is working towards the M.S. degree in the College of Electronic Science and Engineering, National University of Defense Technology, Changsha, Hunan, China. His current research interests involve RF/Microwave circuits, ultra-wide-band technology, microstrip antennas and filters.

Naichang YUAN was born in 1965. He received his M.S. and $\mathrm{Ph} . \mathrm{D}$. degrees in Electronic Science and Technology from the University Science and Technology of China in 1991 and 1994, respectively. He is currently a professor with the College of Electronic Science and Engineering, National University of Defense Technology, Changsha, Hunan, China. His research interests include microwave circuits design, wireless communication and wave propagation. 


\section{Appendix}

\begin{tabular}{|c|c|c|c|c|c|c|c|c|}
\hline $\begin{array}{c}\text { Frequency } \\
{[\mathrm{GHz}]}\end{array}$ & $\begin{array}{c}\text { Calculated } \\
\text { Insert Loss } \\
{[\mathrm{dB}]}\end{array}$ & $\begin{array}{c}\text { Measured } \\
\text { Insert Loss } \\
{[\mathrm{dB}]}\end{array}$ & $\begin{array}{c}\text { Frequency } \\
{[\mathrm{GHz}]}\end{array}$ & $\begin{array}{c}\text { Calculated } \\
\text { Insert Loss } \\
{[\mathrm{dB}]}\end{array}$ & $\begin{array}{c}\text { Measured } \\
\text { Insert Loss } \\
{[\mathrm{dB}]}\end{array}$ & $\begin{array}{c}\text { Frequency } \\
{[\mathrm{GHz}]}\end{array}$ & $\begin{array}{c}\text { Calculated } \\
\text { Insert Loss } \\
{[\mathrm{dB}]}\end{array}$ & $\begin{array}{c}\text { Measured } \\
\text { Insert Loss } \\
{[\mathrm{dB}]}\end{array}$ \\
\hline 3.0 & -9.59 & -40.42 & 5.0 & -0.92 & -0.89 & 7.0 & -0.83 & -2.19 \\
\hline 3.1 & -10.56 & -37.97 & 5.1 & -0.12 & -0.84 & 7.1 & -0.95 & -2.43 \\
\hline 3.2 & -11.41 & -36.30 & 5.2 & -0.80 & -0.88 & 7.2 & -0.93 & -2.30 \\
\hline 3.3 & -12.18 & -34.27 & 5.3 & -1.49 & -0.91 & 7.3 & -0.75 & -2.24 \\
\hline 3.4 & -12.95 & -32.56 & 5.4 & -2.09 & -0.91 & 7.4 & -0.40 & -2.10 \\
\hline 3.5 & -13.75 & -30.15 & 5.5 & -2.57 & -0.97 & 7.5 & -0.09 & -2.16 \\
\hline 3.6 & -14.61 & -28.44 & 5.6 & -2.93 & -1.09 & 7.6 & -0.77 & -2.26 \\
\hline 3.7 & -15.53 & -26.27 & 5.7 & -3.15 & -1.17 & 7.7 & -1.68 & -2.57 \\
\hline 3.8 & -16.45 & -24.42 & 5.8 & -3.23 & -1.16 & 7.8 & -2.87 & -2.63 \\
\hline 3.9 & -17.25 & -22.17 & 5.9 & -3.17 & -1.23 & 7.9 & -4.40 & -2.94 \\
\hline 4.0 & -17.73 & -19.51 & 6.0 & -2.99 & -1.19 & 8.0 & -6.34 & -3.15 \\
\hline 4.1 & -17.64 & -16.94 & 6.1 & -2.70 & -1.31 & 8.1 & -8.81 & -3.41 \\
\hline 4.2 & -16.85 & -13.96 & 6.2 & -2.33 & -1.35 & 8.2 & -11.95 & -3.88 \\
\hline 4.3 & -15.39 & -10.48 & 6.3 & -1.90 & -1.49 & 8.3 & -15.89 & -4.19 \\
\hline 4.4 & -13.45 & -6.62 & 6.4 & -1.43 & -1.51 & 8.4 & -20.48 & -4.74 \\
\hline 4.5 & -11.28 & -3.53 & 6.5 & -0.96 & -1.50 & 8.5 & -23.97 & -9.08 \\
\hline 4.6 & -9.06 & -1.53 & 6.6 & -0.51 & -1.50 & 8.6 & -25.96 & -16.81 \\
\hline 4.7 & -6.92 & -1.01 & 6.7 & -0.09 & -1.59 & 8.7 & -26.14 & -23.19 \\
\hline 4.8 & -4.03 & -0.95 & 6.8 & -0.27 & -1.67 & 8.8 & -25.84 & -29.61 \\
\hline 4.9 & -2.20 & -0.95 & 6.9 & -0.59 & -2.09 & 8.9 & -25.26 & -34.44 \\
\hline
\end{tabular}

Tab. 5. The numerical data of insert loss in Filter 1.

\begin{tabular}{|c|c|c|c|c|c|c|c|c|}
\hline $\begin{array}{c}\text { Frequency } \\
{[\mathrm{GHz}]}\end{array}$ & $\begin{array}{c}\text { Calculated } \\
\text { Insert Loss } \\
{[\mathrm{dB}]} \\
\end{array}$ & $\begin{array}{c}\text { Measured } \\
\text { Insert Loss } \\
{[\mathrm{dB}]} \\
\end{array}$ & $\begin{array}{c}\text { Frequency } \\
{[\mathrm{GHz}]}\end{array}$ & $\begin{array}{c}\text { Calculated } \\
\text { Insert Loss } \\
{[\mathrm{dB}]} \\
\end{array}$ & $\begin{array}{c}\text { Measured } \\
\text { Insert Loss } \\
{[\mathrm{dB}]} \\
\end{array}$ & $\begin{array}{c}\text { Frequency } \\
{[\mathrm{GHz}]}\end{array}$ & $\begin{array}{c}\text { Calculated } \\
\text { Insert Loss } \\
{[\mathrm{dB}]} \\
\end{array}$ & $\begin{array}{c}\text { Measured } \\
\text { Insert Loss } \\
{[\mathrm{dB}]} \\
\end{array}$ \\
\hline 1.0 & -30.73 & -40.55 & 3.0 & -4.98 & -15.45 & 5.0 & -5.14 & -16.38 \\
\hline 1.1 & -17.67 & -38.48 & 3.1 & -3.98 & -18.57 & 5.1 & -5.19 & -14.19 \\
\hline 1.2 & -13.29 & -36.41 & 3.2 & -2.82 & -22.19 & 5.2 & -4.87 & -11.68 \\
\hline 1.3 & -11.26 & -34.26 & 3.3 & -2.27 & -27.02 & 5.3 & -4.18 & -8.79 \\
\hline 1.4 & -10.35 & -32.03 & 3.4 & -2.60 & -33.97 & 5.4 & -3.22 & -5.60 \\
\hline 1.5 & -9.80 & -29.67 & 3.5 & -3.44 & -43.83 & 5.5 & -2.16 & -2.80 \\
\hline 1.6 & -8.81 & -27.08 & 3.6 & -5.09 & -52.46 & 5.6 & -1.14 & -1.52 \\
\hline 1.7 & -6.81 & -24.16 & 3.7 & -7.04 & -47.31 & 5.7 & -0.30 & -1.43 \\
\hline 1.8 & -3.88 & -20.92 & 3.8 & -8.70 & -41.04 & 5.8 & -0.30 & -1.46 \\
\hline 1.9 & -0.39 & -17.16 & 3.9 & -9.48 & -36.96 & 5.9 & -0.61 & -1.67 \\
\hline 2.0 & -1.44 & -12.70 & 4.0 & -9.19 & -33.73 & 6.0 & -0.53 & -3.67 \\
\hline 2.1 & -2.54 & -7.47 & 4.1 & -8.14 & -31.46 & 6.1 & -0.07 & -7.77 \\
\hline 2.2 & -3.09 & -2.62 & 4.2 & -6.86 & -29.74 & 6.2 & -0.76 & -12.28 \\
\hline 2.3 & -3.15 & -0.89 & 4.3 & -5.69 & -28.09 & 6.3 & -1.99 & -16.33 \\
\hline 2.4 & -2.78 & -0.93 & 4.4 & -4.81 & -26.44 & 6.4 & -3.59 & -20.02 \\
\hline 2.5 & -2.01 & -1.08 & 4.5 & -4.28 & -24.90 & 6.5 & -5.51 & -24.07 \\
\hline 2.6 & -0.97 & -2.66 & 4.6 & -4.08 & -23.52 & 6.6 & -7.54 & -28.47 \\
\hline 2.7 & -0.22 & -5.86 & 4.7 & -4.17 & -21.83 & 6.7 & -9.32 & -34.01 \\
\hline 2.8 & -2.29 & -9.29 & 4.8 & -4.47 & -19.99 & 6.8 & -10.41 & -45.05 \\
\hline 2.9 & -4.47 & -12.49 & 4.9 & -4.84 & -18.24 & 6.9 & -10.59 & -48.12 \\
\hline
\end{tabular}

Tab. 6. The numerical data of insert loss in Filter 2. 